\title{
Effects of Intraoperative Ketamine Versus Dexmedetomidine on Release of Inflammatory Mediators in Laparoscopic Hysterectomy. Prospective Randomized Trial
}

Mona Raafat Elghamry ( $\square$ drmonagh19802000@gmail.com )

Tanta University Faculty of Medicine https://orcid.org/0000-0002-7087-864X

Tamer Mohamed Naguib

Tanta University Faculty of Medicine

Taysser Mahmoud AbdAlraheem

Tanta University Faculty of Medicine

Lamees Mohamed Dawood

Tanta University Faculty of Medicine

\section{Research}

Keywords: Dexmedetomidine, Hysterectomy, Inflammatory response, Ketamine, Recovery

Posted Date: October 14th, 2020

DOI: https://doi.org/10.21203/rs.3.rs-90812/v1

License: (9) (i) This work is licensed under a Creative Commons Attribution 4.0 International License.

Read Full License 


\section{Abstract}

Background: Surgery and anesthesia are sources of stress to the patients. Inflammatory reactions to this stress have adverse effects on wound healing and remote organs in addition to long-term sequels e.g. adhesion formation. We compared the effects of dexmedetomidine and ketamine on perioperative level of serum inflammatory biomarkers including tumor necrosis factor-a, interleukin-6, and C- reactive protein.

Methods: We included Seventy-five patients, aged 30-60, ASA I-II, and scheduled for laparoscopic hysterectomy. Patients were randomized to receive intraoperative ketamine (bolus dose $0.25 \mathrm{mg} / \mathrm{kg}$ then continuous infusion $250 \mu \mathrm{g} / \mathrm{kg} / \mathrm{h})$, dexmedetomidine $(1 \mu \mathrm{g} / \mathrm{kg}$ bolus dose then continuous infusion 0.5 $\mu \mathrm{g} / \mathrm{kg} / \mathrm{h}$ ), or placebo. The primary outcome was to measure serum level of inflammatory biomarkers. Hemodynamic parameters, Recovery time, and complications within 24 hours postoperative were recorded.

Results: Whilst there was significant increase in concentrations of inflammatory biomarkers 6 and $24 \mathrm{~h}$ postoperative in all groups, there were significant differences between ketamine and dexmedetomidine group as compared to control group with no significant differences between ketamine and dexmedetomidine group. As regard hemodynamic parameters, there were significant increase in ketamine group and decrease in dexmedetomidine group as compared to base line with no need for medical intervention. There was delayed recovery in ketamine group versus control and dexmedetomidine group $(24.3 \pm 6.4,12.6 \pm 2.0,13.5 \pm 3.3$ min respectively; $P<0.001)$. More complications were reported in ketamine group but did not reach statistical significance.

Conclusion: Dexmedetomidine and ketamine are comparable as regards attenuation of perioperative inflammatory response. However, dexmedetomidine has a favorable safety profile.

Trial registry number is (PACTR201910617459894: date of registration 10/24/2019)

\section{Background}

Stress response to the surgery results in cytokine secretion which has a major role in the inflammatory response to surgery and trauma[1]. In addition, peritoneal injury due to surgery has been associated with the formation of adhesions because it initiates an inflammatory response[2, 3].

Adhesions resulting from gynecological procedures are of major clinical, social, and economic concern, as they may result in pelvic pain, infertility, bowel obstruction and additional surgery to resolve such adhesion-related complications. Although the minimally invasive endoscopic approach has been associated with fewer postoperative adhesions than open surgery, it does not totally eliminate the problem[4]. 
One of the strategies used to reduce systemic cytokine response is to use anesthetic or sub anesthetic dose of general anesthesia or opioid with potential anti-inflammatory effect[5].

Effect of ketamine on perioperative inflammatory response has been widely studied. Recently, dexmedetomidine has been suggested to have anti-inflammatory properties[6] as in vitro studies[7-9] and few human studies (patients in ICU) [10, 11].

The aim of this study is to compare the effect of continuous intraoperative infusion of dexmedetomidine to ketamine on postoperative release of inflammatory biomarkers which include tumor necrosis factor alpha (TNF-a), interleukin-6 (IL-6), and C-reactive protein (CRP) in patients undergoing laparoscopic hysterectomy. In addition, we evaluate the safety profile of both drugs.

We hypothesized that dexmedetomidine could attenuate the inflammatory response to surgery and anesthesia. In addition, dexmedetomidine may have less adverse effects than ketamine.

\section{Methods}

This prospective randomized study was carried out from November 2019 to May 2020 in Tanta University Hospitals. The trial followed the CONSORT 2010 statement guidelines for conducting a randomized controlled trial.

\section{Ethics approval and consent to participate:}

This study was approved by the University's Institutional Review Board (IRB0010038) and written informed consent was obtained from all subjects participating in the trial. The trial was registered prior to patient enrollment. Trial registration (PACTR, No: PACTR201910617459894, Registered 24 October 2019, https://pactr.samrc.ac.za/TrialDisplay.aspx?TrialID=9479).

\section{Consent for publication:}

not applicable

\section{Inclusion criteria:}

Seventy-five female patients, aged 30-60, American Society of Anesthesiologists (ASA) physical status Classification I- II, and scheduled for elective laparoscopic hysterectomy were included in the study. The trial followed the CONSORT 2010 guidelines for conducting a randomized controlled trial.

\section{Exclusion criteria:}

The exclusion criteria included patient refusal, severe respiratory or cardiac disorders, hepatic or renal insufficiency, allergy to any of the study drugs, body mass index $>35 \mathrm{~kg} / \mathrm{m}^{2}$, uncontrolled diabetes, and use of any drug that might affect the immunity as chemotherapy or hormonal treatment. 


\section{Sample size calculation:}

Based on previous study[12], we hypothesized that attenuation in cytokine concentration would be at least $30 \% 6 \mathrm{~h}$ after intravenous dexmedetomidine infusion intraoperative. Therefore, twenty-one patients are required in each group at an alpha value of 0.05 and $90 \%$ power of the study. To overcome the dropped-out cases, 25 patients are included in each group.

Patients were randomized into three equal groups ( 25 patients each) using computer-generated random numbers concealed in sealed opaque envelopes indicating the group of assignment. In group $\mathrm{C}$ (control group), patients received general anesthesia (GA) only while in group K (ketamine group), received racemic ketamine, and those in group $D$ (dexmedetomidine group) received dexmedetomidine.

In the preoperative preparatory room, an intravenous line was established; midazolam $2 \mathrm{mg}$ intravenous was given to all patients. A venous blood sample was withdrawn to determine base line values of tumor necrosis factor-alpha (TNF-a), interleukin-6 (IL-6), C- reactive protein (CRP) which were used as inflammatory biomarkers.

On arrival to the operating theater, monitoring was applied to all participants including electrocardiogram (ECG), non- invasive blood pressure (NIBP) and pulse oximetry (Cardiocaps/5; DatexOhmeda, Helsinki, Finland). Baseline values of heart rate (HR) and mean arterial pressure (MAP) were recorded.

For all patients, GA was induced with fentanyl $1 \mu \mathrm{g} / \mathrm{kg}$, propofol $2 \mathrm{mg} / \mathrm{kg}$ and cisatracurium $0.15 \mathrm{mg} / \mathrm{kg}$. After endotracheal intubation, capnography was added to the previous monitoring. Patients in group $\mathrm{K}$ received racemic ketamine $0.25 \mathrm{mg} / \mathrm{kg}$ as intravenous bolus dose over $10 \mathrm{~min}$ then intravenous infusion at rate of $250 \mu \mathrm{g} \cdot \mathrm{kg}^{-1} \cdot \mathrm{h}^{-1}$ While patients in group D received dexmedetomidine $1 \mu \mathrm{g} / \mathrm{kg}$ as intravenous bolus dose over $10 \mathrm{~min}$ then intravenous infusion at rate of $0.5 \mu \mathrm{g} \cdot \mathrm{kg}^{-1} \cdot \mathrm{h}^{-1}$.

Bolus dose of either drugs was given before the skin incision followed by continuous infusion according to the group of assignment. Anesthesia was maintained by isoflurane $1.5-2 \%$ in $50 \%$ oxygen and cisatracurium $0.03 \mathrm{mg} / \mathrm{kg}$ as required, and ventilator settings were adjusted to keep $\mathrm{EtCO}_{2}$ between 35 and $40 \mathrm{mmHg}$.

After completion of the surgical procedure, ondansetron $4 \mathrm{mg}$ intravenous was given and tracheal extubation was done after reversal of neuromuscular block and fulfillment of extubation criteria.

All patients were transferred to the post-anesthesia care unit (PACU) and they were transferred to surgical ward according to modified Aldrete score (if score is $\geq 9$ )

Our primary outcome was to assess inflammatory biomarkers TNF-a, IL-6, CRP at the following points: T1; base line before induction of anesthesia, T2; 6 hours after injection of the study drugs, T3; 24 hours after injection of the study drugs. 
Venous blood samples were collected in into EDTA tubes. Blood samples from each subject were collected simultaneously over 10-20 minutes. Samples were immediately placed on ice and centrifuged at $2000 \mathrm{~g}$ for 10 minutes and then plasma was frozen and stored at $-70 \mathrm{C}^{\circ}$ until further analyzes which were performed within 10 days after collection. The sandwich ELISA (enzyme-linked immunosorbent assay) method using commercially available tests (Quantikine ELISA Kit, R\&D Systems, Minneapolis, USA) was applied for determination of TNF-a, IL-6, CRP levels. The absorbance measurements were performed with a use of the photometer for microplates Elx 800 by Bio-Tek Instruments (USA). The absorbance values were read for the wavelength of $\lambda=450 \mathrm{~nm}$ with $\Lambda$ correction 540 or $570 \mathrm{~nm}$. The absorbance was converted into concentration units based upon a standard curve.

Secondary measurements were MAP and HR, which were measured at the following points: baseline before induction of anesthesia (T0), immediately after intubation (T1), immediately after end of bolus dose of the study drugs (T2), then every 10 min until the end of surgery. Recovery time was measured from discontinuation of anesthesia and reversal of muscle relaxant until transfer to PACU. Any adverse effects like postoperative nausea and vomiting (PONV), Hypotension (MAP $<65 \mathrm{mmHg}$ ), bradycardia ( $\mathrm{HR}<50$ beat/min), over-sedation, and psychomimetic change as agitation, hallucinations, or vivid dreams up to $24 \mathrm{~h}$ after the surgery) were recorded.

\section{Statistical analysis}

Data were fed to the computer and analyzed using IBM SPSS software package version 20.0. (Armonk, NY: IBM Corp). The Kolmogorov-Smirnov test was used to verify the normality of distribution of variables; Comparisons between groups for categorical variables were assessed using Chi-square test (Fisher or Monte Carlo). ANOVA was used to compare more than two groups for normally distributed quantitative variables and followed by Post Hoc test (Tukey) for pairwise comparison. ANOVA with repeated measures and Post Hoc test (adjusted Bonferroni) was assessed for comparison between different periods Significance of the obtained results was judged at the $5 \%$ level.

\section{Results}

Over the duration of six months, 83 patients were assessed for eligibility but only 75 patients were chosen for the analysis. Three patients did not meet inclusion criteria and five patients refused to participate in the study. Fortunately, no patients were lost during the follow up. The patients were randomly allocated in one of the three groups. Finally, 25 patients in each group were analyzed as shown in CONSORT flow diagram Fig. 1.

The study groups were comparable as regard to age, body mass index, and duration of the surgery [Table 1].

Whilst there were significant increase in the concentrations of inflammatory biomarkers (TNF- $a$, IL- 6 , and CRP) 6 and $24 \mathrm{~h}$ postoperative in the 3 studied groups, there were significant differences between ketamine group and dexmedetomidine group as compared to the control group with no significant 
differences between ketamine group and dexmedetomidine group. The results indicated that ketamine and dexmedetomidine could attenuate the early postoperative inflammatory response [Table 2].

It has been found that hemodynamic parameters (HR and MAP) were significantly increased as compared to the baseline values in ketamine group while in dexmedetomidine group; hemodynamic parameters were significantly decreased as compared to the baseline values. The patients were clinically stable and did not need any intervention. The overall measurement results are summarized in Figs. 3 and 4.

Significant delayed recovery in ketamine group $(24.3 \pm 6.4 \mathrm{~min})$ as compared to the control group (12.6 \pm $2.0 \mathrm{~min})$ and dexmedetomidine group $(13.5 \pm 3.3 \mathrm{~min})$ [Table 1].

The results showed that there were no significant differences between the studied group as regard the adverse effects. More adverse effects reported in the ketamine group (agitation in one patient, nausea in six patients, vomiting in two patients). Although it was statistically non-significant, it is of clinical importance [Table 3].

\section{Availability of data and materials:}

The datasets used and / or analyzed during the current study are available from the corresponding author on reasonable request.

\section{Discussion}

Dexmedetomidine is an alpha ${ }_{2}$-adrenergic agonist, which has an analgesic, sedative, and sympatholytic effect. In addition, animal studies demonstrated the anti-inflammatory effect of dexmedetomidine $[9,13]$.

Up to our knowledge, it is the first study to compare the effect of dexmedetomidine and ketamine on suppression of inflammatory response (release of inflammatory biomarkers, including TNF-a, IL-6, and $\mathrm{CRP}$ ) in female patients undergoing laparoscopic hysterectomy. In addition, we assessed the side effects of both drugs.

The choice of TNF-a and IL- 6 to be assessed was due to their very early involvement in the initiation of inflammatory response[14]. In addition, IL-6 is not affected by anesthetic interventions alone, so it reflects the surgery-induced stress[15].

We found that dexmedetomidine was able to mitigate the early postoperative inflammatory response. Also, earlier studies were reported that dexmedetomidine decreased TNF- $\mathrm{a}$ and IL- 6 concentrations in rats with sepsis[13,16] and alleviated inflammation in a rat model with spinal cord injury[7]. Furthermore, it significantly decreased the development of postoperative intraabdominal adhesions in rats with abdominal surgery[17]. This anti-inflammatory effect of dexmedetomidine was demonstrated also in clinical trials, where its administration postoperatively to patients requiring sedation and mechanical 
ventilation was associated with decreased concentrations of IL-6 levels[11]. Dexmedetomidine was reported also to decrease IL-1, TNF-a, and IL-6 concentrations in patients with sepsis[18].

Few studies have evaluated the anti-inflammatory effects of dexmedetomidine on surgery-induced inflammatory response, whose results were consistent with our study. Kang et al.[1] found that patients undergoing laparoscopic cholecystectomy who received dexmedetomidine had significantly lower concentrations of IL-1 $\beta$, TNF-a, IL-10, and CRP with lower leukocytic count compared to the control participants. Ueki et al.[6] demonstrated that dexmedetomidine reduced the increase in postoperative IL-6 levels in patients undergoing cardiopulmonary bypass. Ding et al.[19] found dexmedetomidine to significantly decrease TNF- $a$ and IL- 6 compared to the control group in elderly patients undergoing laparoscopic radical prostatectomy. Li et al.[20] reported that dexmedetomidine reduced significantly the intraoperative and postoperative levels of TNF- $a$ and IL- 6 in patients undergoing open gastrectomy. Jiang et al.[21] stated that dexmedetomidine had significantly decreased IL-6 levels after open esophagectomy.

The mechanism of the anti-inflammatory effect of dexmedetomidine is not completely understood. Dexmedetomidine was postulated to modify the production of cytokines by macrophages and monocytes[22]. In addition, it was found to possess an antiapoptotic effect, which may contribute to protection against anesthetic-induced apoptosis in vivo and in vitro[23].

Moreover, dexmedetomidine could augment the phagocytic activity of macrophages in vitro[24]. Dexmedetomidine may also suppress inflammation through a central sympatholytic effect by stimulation of the cholinergic anti-inflammatory pathway[25]. Another proposed mechanism is inhibition of nuclear factor kappa B activation[26]. It might be possible that the antinociceptive action of dexmedetomidine contributes to its anti-inflammatory effect[27].

Ketamine is an anesthetic and analgesic drug with anti-inflammatory effect[28]. A meta-analysis concluded that ketamine has a significant inhibitory effect on postoperative IL- 6 levels and thereby mitigates the early inflammatory response after surgery[5]. Moreover, ketamine has been shown to decrease the postoperative levels of TNF- $a$, IL-1 $\beta$, IL-6[29]. The current study showed that ketamine and dexmedetomidine suppressed the increase in the postoperative level of inflammatory markers, with no significant differences. This finding indicates that both drugs could be equally effective in attenuation of postoperative inflammatory response.

In our study, all patients were clinically stable and none needs any intervention, although HR and MAP were significantly increased in ketamine group and significantly decreased in dexmedetomidine group compared to the baseline values. Similar hemodynamic effects of dexmedetomidine were observed in several studies[19, 20,30,31]. This is considered a myocardial protective effect of dexmedetomidine as it prevents the acute increases during airway management, reduces myocardial oxygen demand, and decreases the risk of myocardial injury[32].

We found that the recovery time was slightly higher in the dexmedetomidine group (13.5 $\pm 3.3 \mathrm{~min}$ ) compared to the control group $(12.6 \pm 2.0 \mathrm{~min})$, whereas the recovery time was significantly longer in the 
ketamine group $(24.3 \pm 6.4 \mathrm{~min})$ than in the other two groups. In partial agreement to our results, previous studies showed that dexmedetomidine when co-administered with propofol associated with a longer recovery time from anesthesia[33,34]. The lack of significant difference in recovery time between the dexmedetomidine and control groups in our study may be attributed to the used protocol that differed from other studies. Delayed recovery time with ketamine administration was reported even with subanesthetic doses[35].

Various adverse effects were reported with dexmedetomidine administration, including cardiovascular (e.g., bradycardia, hypertension, dysrhythmias), gastrointestinal (e.g., vomiting, dry mouth), respiratory (e.g., pleural effusion, atelectasis, pulmonary edema), and metabolic adverse effects (e.g., hyperglycemia, hypocalcaemia, and acidosis). Cardiovascular effects of dexmedetomidine are related to its administration with rapid infusion rate or with large bolus dose[36, 37].

As for ketamine, adverse effects were reported on the respiratory system (e.g., apnea) gastrointestinal system (e.g., PONV), and recovery from anesthesia (emergence agitation) [38].

Evaluation of the adverse effects in our study elicited no significant differences among the studied groups. However, more adverse effects were recorded in the ketamine group. This difference in adverse events may bear clinical importance despite being statistically insignificant. Dexmedetomidine has been shown to prevent emergence agitation[34] and postoperative vomiting[39] more effectively than ketamine. These findings suggest that dexmedetomidine is safe and may be preferred over ketamine for having lower rate of adverse effects as well as maintenance of hemodynamic stability with myocardial protective effect and control of emergence agitation.

\section{Limitations Of The Study}

First, short term follow up of anti-inflammatory effect of the study drugs. Second, the study did not investigate the mechanism of action of the study drugs

Further studies are proposed to compare different doses of dexmedetomidine and ketamine to know the minimum effective dose given by either continuous infusion or single injection. Furthermore, by evaluation of more inflammatory biomarkers the mechanism of action of dexmedetomidine could be concluded.

\section{Conclusion}

Dexmedetomidine and ketamine were comparable to each other as regards attenuation of the postoperative inflammatory response. However, the safety profile of dexmedetomidine seems favorable over that of ketamine as evidenced by the former's lower rate of adverse effects with maintenance of hemodynamic stability.

\section{List Of Abbreviations}




\begin{tabular}{|ll|}
\hline ASA & American Society of Anesthesiologists \\
\hline CRP & C-reactive protein \\
\hline ECG & Electrocardiogram \\
\hline ELISA & Enzyme-linked immunosorbent assay \\
\hline GA & General anesthesia \\
\hline HR & Heart rate \\
\hline IL-6 & Interleukin-6 \\
\hline MAP & Mean arterial pressure \\
\hline NIBP & Non- invasive blood pressure \\
\hline PACU & Post-anesthesia care unit \\
\hline PONV & Postoperative nausea and vomiting \\
\hline TNF-a & Tumor necrosis factor-a \\
\hline
\end{tabular}

\section{Declarations}

\section{Author's contributions:}

1. M R E: contributed in conceptualization of the study, helped design the study and the protocol, collect and interpret the data, and draft the article.

2. T M N: helped conduct of the study, analyzed the data, and writing the manuscript.

3. T M A: helped conduct of the study, collect and analyze the data and review the manuscript.

4. L M D: This author helped collect and analyze the data, conduct the laboratory investigations and review the manuscript.

The manuscript has been read and finally approved by all the authors.

\section{Competing interests:}

The authors declare that they have no competing interests

\section{Funding:}

None

\section{Acknowledgement:}

not applicable 


\section{References}

1. Kang SH, Kim YS, Hong TH,Chae MS, Cho ML, Her YM, et al. Effects of dexmedetomidine on inflammatory responses in patients undergoing laparoscopic cholecystectomy. Acta Anaesth Scand. 2013;57(4):480-7. https://doi.org/10.1111/aas.12039

2. Arung W, Meurisse M, Detry O. Pathophysiology and prevention of postoperative peritoneal adhesions. World J Gastroenterol. 2011;17(41):4545-53. https://doi.org/10.3748/wjg.v17.i41.4545

3. Robertson D, Lefebvre G, Leyland N, Wolfman W, Allaire C, Awadalla A, et al. Adhesion prevention in gynaecological surgery. Int J Gynecol Obstet. 2010;111(2):193-7.

https:// doi.org/10.1016/j.ijgo.2010.07.002

4. Nappi C, Di Spiezio Sardo A, Greco E, Guida M, Bettocchi S, Bifulco G. Prevention of adhesions in gynaecological endoscopy. Hum Reprod Update. 2007;13(4):379-94.

https://doi.org/10.1093/humupd/dml061

5. Dale O, Somogyi AA, Li Y, Sullivan T, Shavit Y. Does intraoperative ketamine attenuate inflammatory reactivity following surgery? A systematic review and meta-analysis. Anesth Analg. 2012;115(4):93443.https://doi.org/ 10.1213/ANE.0b013e3182662e30

6. Ueki M, Kawasaki T, Habe K, Hamada K, Kawasaki C, Sata T. The effects of dexmedetomidine on inflammatory mediators after cardiopulmonary bypass. Anaesthesia. 2014;69(7):693-700. https://doi.org/10.1111/anae.12636

7. Can M, Gul S, Bektas S, Hanci V, Acikgoz S. Effects of dexmedetomidine or methylprednisolone on inflammatory responses in spinal cord injury. Acta Anaesth Scand. 2009;53(8):106872.https://doi.org/10.1111/j.1399-6576.2009.02019.x

8. Eser O, Fidan H, Sahin O, Cosar M, Yaman M, Mollaoglu H, et al. The influence of dexmedetomidine on ischemic rat hippocampus. Brain Res. 2008;1218:250-6.

https://doi.org/10.1016/j.brainres.2008.04.045

9. Taniguchi T, Kurita A, Kobayashi K, Yamamoto K, Inaba H. Dose and time related effects of dexmedetomidine on mortality and inflammatory responses to endotoxin-induced shock in rats. $\mathrm{J}$ Anesth. 2008;22(3):221-8. https://doi.org/10.1007/s00540-008-0611-9

10. Memiş D, Hekimoğlu S, Vatan I, Yandım T, Yüksel M, Süt N. Effects of midazolam and dexmedetomidine on inflammatory responses and gastric intramucosal $\mathrm{pH}$ to sepsis, in critically ill patients. Brit J Anaesth. 2007;98(4):550-2. https://doi.org/10.1093/bja/aem017

11. Venn R, Bryant A, Hall GM, Grounds R. Effects of dexmedetomidine on adrenocortical function, and the cardiovascular, endocrine and inflammatory responses in postoperative patients needing sedation in the intensive care unit. Brit J Anaesth. 2001;86(5):650-6.

https://doi.org/10.1093/bja/86.5.650

12. Roytblat L, RoyShapira A, Greemberg L, Korotkoruchko A, Schwartz A, Peizer, J, et al. Preoperative low dose ketamine reduces serum interleukin- 6 response after abdominal hysterectomy. The Pain Clinic. 1996;9(3):327-34. 
13. Qiao H, Sanders RD, Ma D, Wu X, Maze M. Sedation improves early outcome in severely septic Sprague Dawley rats. Crit Care. 2009;13(4):R136. https://doi.org/10.1186/cc8012

14. Han C, Ding Z, Fan J, Sun J, Qian Y. Comparison of the stress response in patients undergoing gynecological laparoscopic surgery using carbon dioxide pneumoperitoneum or abdominal walllifting methods. J Laparoendosc Adv S. 2012;22(4):330-5.https://doi.org/10.1089/lap.2011.0412

15. Fu E, Norman J, Scharf J, Burdash N. Effect of type of anesthesia and lower abdominal laparotomy in mice on the cytokine response to acute stress. Region Anesth Pain M. 1996;21(5):4703.http://doi.org/10.1136/rapm-00115550-199621050-00014

16. Taniguchi T, Kidani Y, Kanakura H, Takemoto Y, Yamamoto K. Effects of dexmedetomidine on mortality rate and inflammatory responses to endotoxin-induced shock in rats. Crit Care Med. 2004;32(6):1322-6. http://doi.org/ 10.1097/01.CCM.0000128579.84228.2A

17. Kuru S, Bozkirli OB, Barlas AM, Duymus ME, Senes M, Yumusak N, et al. The preventive effect of dexmedetomidine against postoperative intra-abdominal adhesions in rats. Int Surg. 2015;100(1):8795 http://doi.org/ 10.9738/INTSURG-D-14-00184.1.

18. Tasdogan M, Memis D, Sut N, Yuksel M. Results of a pilot study on the effects of propofol and dexmedetomidine on inflammatory responses and intra-abdominal pressure in severe sepsis. J Clin Anesth. 2009;21(6):394-400. https://doi.org/10.1016/j.jclinane.2008.10.010

19. Ding L, Zhang H, Mi W, He Y, Zhang X, Ma X, et al. Effects of dexmedetomidine on recovery period of anesthesia and postoperative cognitive function after robot-assisted laparoscopicradical prostatectomy in the elderly people. J Cent South Univ. 2015;40(2):129-35. https://doi.org/10.11817/j.issn.1672-7347.2015.02.003

20. Y Li, B Wang, L Zhang, S He, X Hu, G Wong, et al. Dexmedetomidine combined with general anesthesia provides similar intraoperative stress response reduction when compared with a combined general and epidural anesthetic technique. Anesth Analg. 2016;122(4):120210.https://doi.org/10.1213/ANE.0000000000001165

21. Jiang W, Han C, Jiang W, et al. A comparion of the effects of dexmedetomedine and propofol on stress response in patients undergoing open esophagectomy under total intravenous anesthesia: a randomized controlled trail. Int J Clin Exp Med. 2016;9(3):6545-50.ISSN:1940-5901/IJCEM0019096

22. Maes M, Lin A, Kenis G, Egyed B, Bosmans $E$. The effects of noradrenaline and alpha- ${ }_{2}$ adrenoceptor agents on the production of monocytic products. Psychiat Res. 2000;96(3):245-53. https://doi.org/10.1016/S0165-1781(00)00216-X

23. Sanders RD, Xu J, Shu Y, Januszewski A, Halden S, Fidalgo A, et al. Dexmedetomidine attenuates isoflurane-induced neurocognitive impairment in neonatal rats. Anesthesiology. 2009;110(5):107785. https://doi.org/10.1097/ALN.0b013e31819daedd

24. Weatherby KE, Zwilling BS, Lafuse WP. Resistance of macrophages to Mycobacterium avium is induced by $\mathrm{a}_{2}$-adrenergic stimulation. Infect Immun. 2003;71(1):229.https://doi.org/10.1128/IAl.71.1.22-29.2003 
25. Tracey KJ. Physiology and immunology of the cholinergic antiinflammatory pathway. J Clin Invest. 2007;117(2):289-96.https://doi.org/10.1172/JCl30555.

26. Kawasaki T, Kawasaki C, Ueki M, Hamada K, Habe K, Sata T. Dexmedetomidine suppresses proinflammatory mediator production in human whole blood in vitro. J Trauma Acute Care Surg. 2013;74(5):1370-5. https://doi.org/10.1097/TA.0b013e31828db978

27. Shavit $Y$, Fridel K, Beilin B. Postoperative pain management and proinflammatory cytokines: animal and human studies. J Neuroimmune Pharm. 2006;1(4):443-51.https://doi.org/10.1007/s11481-0069043-1

28. Loix S, De Kock M, Henin P. The anti-inflammatory effects of ketamine: state of the art. Acta Anaesthesiol Belg. 2011;62(1):47-58. PMID: 21612145

29. Kartalov A, Trajkov D, Spiroski M, Nikolova Todorova Z, Kuzmanovska B, Dzambazovska Trajkovska $V$, et al. The effect of a small dose of ketamine on postoperative analgesia and cytokine changes after laparoscopic cholecystectomy. Sec Biol Med Sci. 2012;33(1):217-29. PMID: 22983102

30. Menda F, Koner O, Sayin M, Ture H, Imer P, Aykac B. Dexmedetomidine as an adjunct to anesthetic induction to attenuate hemodynamic response to endotracheal intubation in patients undergoing fast-track CABG. Ann Card Anaesth. 2010;13(1):16-21. https://doi.org/10.4103/0971-9784.58829

31. Patel CR, Engineer SR, Shah BJ, Madhu S. Effect of intravenous infusion of dexmedetomidine on perioperative haemodynamic changes and postoperative recovery: A study with entropy analysis. Indian J Anaesth. 2012;56(6):542-6. https://doi.org/ 10.4103/0019-5049.104571

32. Xu L, Hu Z, Shen J, McQuillan PM. Does dexmedetomidine have a cardiac protective effect during non-cardiac surgery? A randomised controlled trial. Clin Exp Pharmacol Physiol. 2014;41(11):87983.https://doi.org/10.1111/1440-1681.12296

33. Ohtani N, Kida K, Shoji K, Yasui Y, Masaki E. Recovery profiles from dexmedetomidine as a general anesthetic adjuvant in patients undergoing lower abdominal surgery. Anesth Analg. 2008;107(6):1871-4. https://doi.org/ 10.1213/ane.0b013e3181887fcc

34. Kim S, Kim J, Lee J, Song B, Koo B. Efficacy of intraoperative dexmedetomidine infusion on emergence agitation and quality of recovery after nasal surgery. Brit J Anaesth. 2013;111(2):2228.https://doi.org/10.1093/bja/aet056

35. Pradeep, Raveendra U S. Assessment of recovery from anaesthesia with analgesic doses of ketamine: A randomized controlled study. MedPulse International Journal of Anesthesiology. 2017;4(1):1-4.https://doi.org/10.26611/1015411

36. Kaur M, Singh P. Current role of dexmedetomidine in clinical anesthesia and intensive care. Anesth Essays Res. 2011;5(2):128-33. https://doi.org/10.4103/0259-1162.94750

37. Lee S. Dexmedetomidine: present and future directions. Korean J Anesthesiol. 2019;72(4):32330.https://doi.org/10.4097/kja.19259

38. Lemoel F, Contenti J, Giolito D, Boiffier M, Rapp J, Istria J, et al. Adverse Events With Ketamine Versus Ketofol for Procedural Sedation on Adults: A Double-blind, Randomized Controlled Trial. Acad Emerg Med. 2017;24(12):1441-9. https://doi.org/10.1111/acem.13226 
39. Chen J-Y, Jia J-E, Liu T-J, Qin M-J, Li W-X. Comparison of the effects of dexmedetomidine, ketamine, and placebo on emergence agitation after strabismus surgery in children. Can J Anaesth. 2013;60(4):385-92. https://doi.org/10.1007/s12630-013-9886-x

\section{Tables}

Table 1:

Comparison of the Patients' charachteristics, Duration of Surgery, and Recovery Time Between the Three Groups.

\begin{tabular}{|c|c|c|c|c|}
\hline Parameter & $\begin{array}{l}\text { Control } \\
(n=25)\end{array}$ & $\begin{array}{l}\text { Ketamine } \\
(n=25)\end{array}$ & $\begin{array}{l}\text { Dexmedetomidine } \\
(n=25)\end{array}$ & $P$ \\
\hline Age & $45.2 \pm 8.7$ & $45.7 \pm 8.9$ & $45.0 \pm 8.6$ & 0.964 \\
\hline BMI & $29.6 \pm 3$ & $28.8 \pm 2.8$ & $28.6 \pm 2.5$ & 0.352 \\
\hline Duration & $139.4 \pm 14.1$ & $137.4 \pm 12.9$ & $140.2 \pm 11.7$ & 0.734 \\
\hline Recovery time (min) & $12.6^{\mathrm{b}} \pm 2.0$ & $24.3^{\mathrm{a}} \pm 6.4$ & $13.5^{\mathrm{b}} \pm 3.3$ & $<0.001^{*}$ \\
\hline \multicolumn{5}{|c|}{$\begin{array}{l}\text { BMI: body mass index; } \mathrm{n}=\text { patient's number; } P \text {. } \mathrm{P} \text { value for comparing between the studied groups } \\
\text { statistically significant at } \mathrm{p} \leq 0.05 \text {. } \\
\text { data presented as mean } \pm \text { standard deviation. } \\
\text { means with common letters are not significant (i.e. means with different letters are significant). }\end{array}$} \\
\hline
\end{tabular}


Table 2:

Comparison of Serum Level of Inflammatory Biomarkers Between the Three Studied Groups.

\begin{tabular}{|c|c|c|c|c|}
\hline $\begin{array}{l}\text { Inflammatory } \\
\text { Biomarkers }\end{array}$ & $\begin{array}{l}\text { Control } \\
(n=25)\end{array}$ & $\begin{array}{l}\text { Ketamine } \\
(n=25)\end{array}$ & $\begin{array}{l}\text { Dexmedetomidine } \\
(n=25)\end{array}$ & $P$ \\
\hline \multicolumn{5}{|l|}{ IL-6 } \\
\hline Baseline & $45.5 \pm 8.5$ & $45.7 \pm 8$ & $43.9 \pm 7.1$ & 0.664 \\
\hline 6 hour & $113.4^{\#} \pm 14.1$ & $50.1^{\mathrm{a} \#} \pm 8.1$ & $47.7^{a \#} \pm 7.1$ & $<0.001^{*}$ \\
\hline 24 hour & $107.4^{\#} \pm 13.7$ & $48.2^{\mathrm{a} \#} \pm 8.1$ & $46.01^{\mathrm{a} \#} \pm 7.1$ & $<0.001^{*}$ \\
\hline \multicolumn{5}{|l|}{ TNF- $a$} \\
\hline Baseline & $38.2 \pm 8.7$ & $37 \pm 6.8$ & $37.33 \pm 7.7$ & 0.835 \\
\hline 6 hour & $81.8^{\#} \pm 18.6$ & $40.6^{\mathrm{a} \#} \pm 7.1$ & $41.6^{a \#} \pm 7.6$ & $<0.001^{*}$ \\
\hline 24 hour & $72.7^{\#} \pm 16.4$ & $39.2^{\mathrm{a} \#} \pm 6.9$ & $39.9^{\mathrm{a} \#} \pm 7.6$ & $<0.001^{*}$ \\
\hline \multicolumn{5}{|l|}{ CRP } \\
\hline Baseline & $5.0 \pm 1.04$ & $4.7 \pm 0.5$ & $4.9 \pm 1.04$ & 0.450 \\
\hline 6 hour & $17.4^{\#} \pm 3.6$ & $10.2^{\mathrm{a} \#} \pm 1.3$ & $10.9^{a \#} \pm 1.8$ & $<0.001^{*}$ \\
\hline 24 hour & $40.0^{\#} \pm 6.0$ & $16.2^{\mathrm{a} \#} \pm 1.2$ & $16.3^{\mathrm{a} \#} \pm 1.9$ & $<0.001^{*}$ \\
\hline $\begin{array}{l}\text { CRP: C-reactive } \\
\text { statistically sig } \\
\text { each group. } \\
\text { a: statistically } \\
\text { b: statistically s } \\
\text { data presented }\end{array}$ & $\begin{array}{l}\text { in; IL-6: interleu } \\
\text { nt at } p \leq 0.05 \text {; } \\
\text { cant with contr } \\
\text { cant with ketam } \\
\text { ean } \pm \text { standard }\end{array}$ & $\begin{array}{l}n=\text { number of } \\
\text { istically signifi } \\
\text { p. } \\
\text { oup. } \\
\text { on. }\end{array}$ & $\begin{array}{l}\text { nts; TNF-a: tumor ne } \\
\text { with baseline and eac }\end{array}$ & $\begin{array}{l}\text { actor-a; } \\
\text { r periods in }\end{array}$ \\
\hline
\end{tabular}


Table 3:

Comparison Between the Three Studied Groups According to Adverse Effects.

\begin{tabular}{|lllll|}
\hline Adverse effects & $\begin{array}{c}\text { Control } \\
(\mathrm{n}=25)\end{array}$ & $\begin{array}{l}\text { Ketamine } \\
(\mathrm{n}=25)\end{array}$ & $\begin{array}{l}\text { Dexmedetomidine } \\
(\mathrm{n}=25)\end{array}$ & $\boldsymbol{P}$ \\
\hline Agitation & $0(0.0 \%)$ & $1(4.0 \%)$ & $0(0.0 \%)$ & 1.000 \\
\hline Nausea & $2(8.0 \%)$ & $6(24.0 \%)$ & $1(4.0 \%)$ & 0.126 \\
\hline Vomiting & $1(4.0 \%)$ & $2(8.0 \%)$ & $0(0.0 \%)$ & 0.776 \\
\hline & & & \\
\hline
\end{tabular}

Figures 


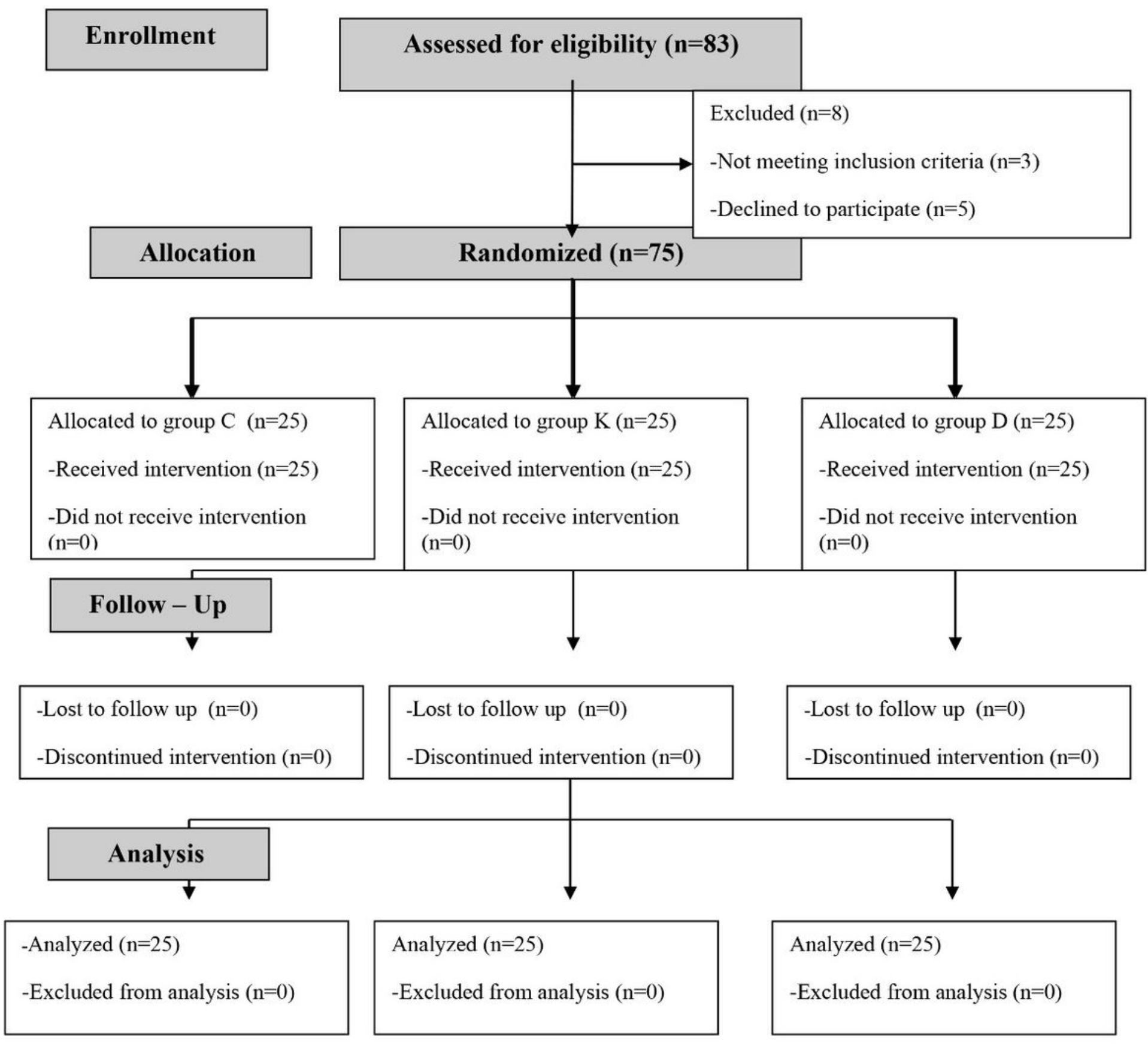

Figure 1

CONSORT flow diagram of participants through each stage of the randomized trial. 


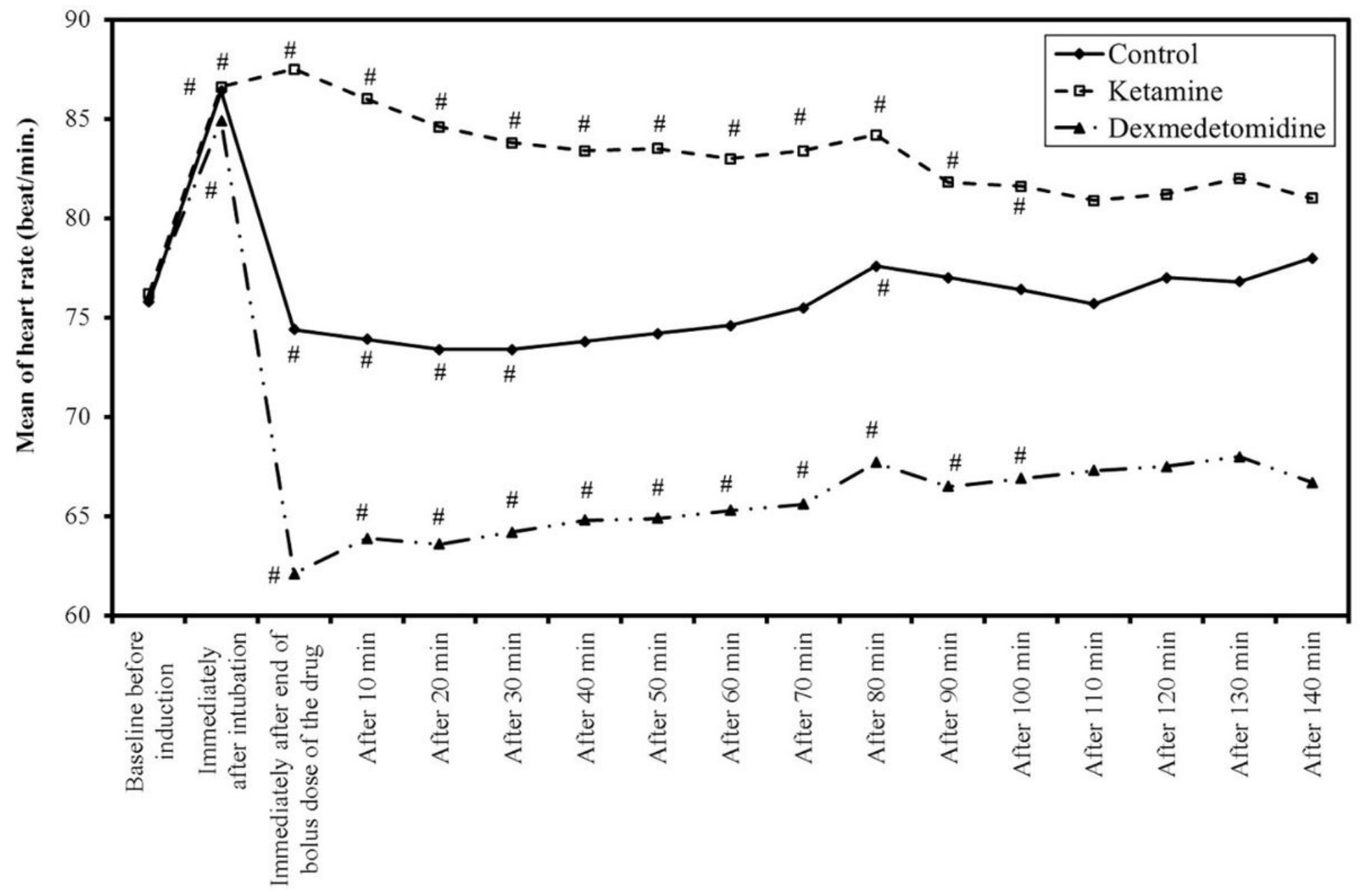

Figure 2

Comparison of heart rate (beat/min) changes in the three groups. Data presented as mean \pm standard deviation. 


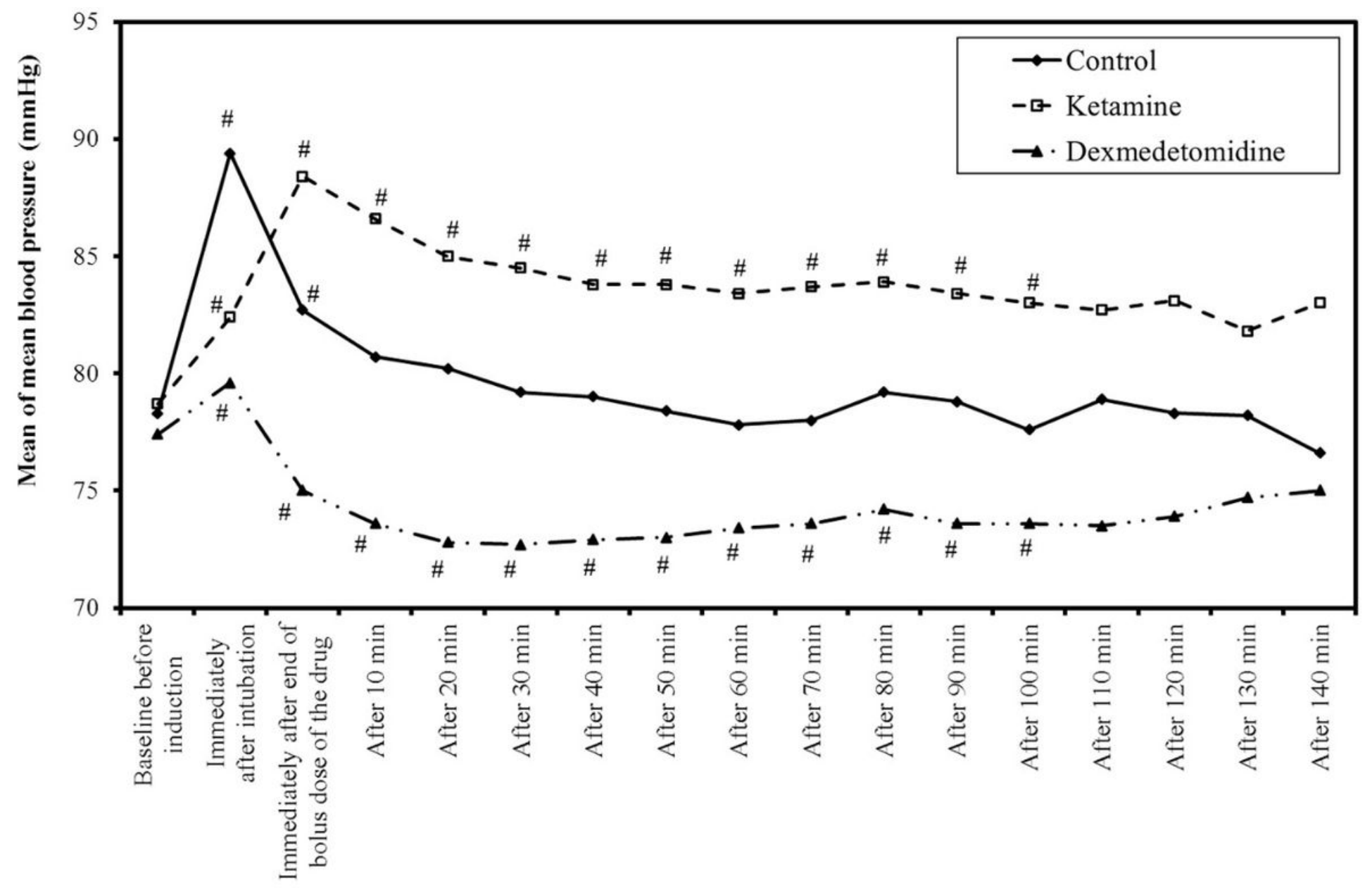

Figure 3

Comparison of mean arterial pressure $(\mathrm{mmHg})$ changes in the three groups. Data presented as mean \pm standard deviation. 